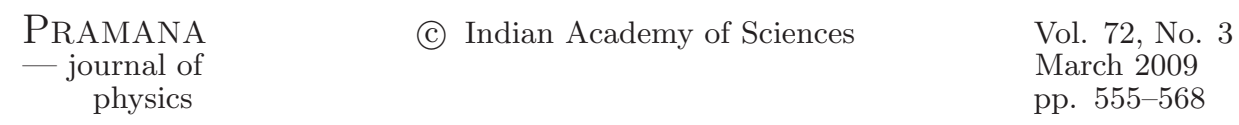

\title{
The effect of composition, electron irradiation and quenching on ionic conductivity in a new solid polymer electrolyte: $(\mathrm{PEG})_{x} \mathrm{NH}_{4} \mathrm{I}$
}

\author{
$\mathrm{R}^{\mathrm{DAMLE}}{ }^{1, *}, \mathrm{P}^{\mathrm{N}} \mathrm{KULKARNI}^{1}$ and $\mathrm{S} \mathrm{V}_{\mathrm{BHAT}}{ }^{2}$ \\ ${ }^{1}$ Department of Physics, Bangalore University, Bangalore 560 056, India \\ ${ }^{2}$ Department of Physics, Indian Institute of Science, Bangalore 560 012, India \\ ${ }^{*}$ Corresponding author. E-mail: ramkrishnadamle@bub.ernet.in
}

MS received 1 July 2008; accepted 2 January 2009

\begin{abstract}
We have prepared, characterized and investigated a new PEG-2000 based solid polymer electrolyte $(\mathrm{PEG})_{x} \mathrm{NH}_{4} \mathrm{I}$. Ionic conductivity measurements have been made as a function of salt concentration as well as temperature in the range $265-330 \mathrm{~K}$. Selected compositions of the electrolyte were exposed to a beam of $8 \mathrm{MeV}$ electrons to an accumulated dose of $10 \mathrm{kGy}$ to study the effect on ionic conductivity. The electrolyte samples were also quenched at liquid nitrogen temperature and conductivity measurements were made. The ionic conductivity at room temperature exhibits a characteristic double peak for the composition $x=20$ and 70 . Both electron beam irradiation and quenching at low temperature have resulted in an increase in conductivity by $1-2$ orders of magnitude. The enhancement of conductivity upon irradiation and quenching is interpreted as due to an increase in amorphous region and decrease in crystallinity of the electrolyte. DSC and proton NMR measurements also support this conclusion.
\end{abstract}

Keywords. Solid polymer electrolytes; ionic conductivity; conductivity enhancement.

PACS Nos 66.10.Ed; 82.35.Cd; 82.35.Rs

\section{Introduction}

Ever since the first observation of high ionic conductivity in solid polymer electrolytes (SPE) in 1973, solvent-free polymer electrolytes have been an active topic of research $[1,2]$. SPEs have received considerable attention due to their valuable applications in high energy density batteries and electrochemical devices. A large number of SPEs have been studied till date [3]. Among these, poly(ethylene oxide) (PEO) has been widely studied as a host polymer complexed with alkali salts (lithium salt being the most studied) for use in all solid-state lithium batteries [4-8]. However, the disadvantage of these SPEs is the insufficient ionic conductivity although they have the advantage of most other properties being suitable for applications. Research and development are in constant progress in many ways to improve the ionic conductivity to attain a value $\sim 10^{-3} \mathrm{~S} / \mathrm{cm}$ for practical use as 


\section{$R$ Damle, $P N$ Kulkarni and $S V$ Bhat}

secondary lithium ion battery. Thus, the search for new SPEs and optimization of room temperature conductivity are still an active field of research. Ionic conductivity in SPEs can be improved either by lowering the glass transition temperature $\left(T_{\mathrm{g}}\right)$ of the polymer or by lowering the energy barrier for ionic movement. Several strategies have been suggested to achieve this which include (1) addition of plasticizers [9,10], (2) addition of nanosized ceramic fillers [11-15], (3) incorporating organic solvents [16], (4) exposure of SPEs to high energy ionizing radiation [17], (5) quenching at low temperature and (6) synthesizing new polymers or salts [18].

It is generally known that conductivity in SPEs is influenced by the concentration of defects and also the fraction of the amorphous region in the system [19]. Exposure of SPEs to high energy ionizing radiation has been tried out earlier to increase the amorphous content and decrease the crystallinity of the system [17].

Most of the studies of concentration and temperature dependence and enhancement of conductivity have been on high molecular weight host polymers. However, much attention has not been paid to the somewhat low molecular weight (MW 2000) polymers. Shi and Vincent [20] have studied the effect of molecular weight of polymers on cation mobility and have shown that above a critical limit of 3200 , the MW has no significant effect on cation mobility. However, below this limit, due to different viscosity and diffusion behaviours, an additional transport mechanism could be operating. In this low molecular weight region, referred to as the Rouse region, there is a possibility of the polymer chain diffusion besides the segmental motion. While PEO as host polymer complexed with alkali salts is well studied, there appears to be rather little focus on poly(ethylene glycol) (PEG) as a host polymer $[21,22]$. PEG has the same monomeric unit as PEO but has an end hydroxyl group, with the chemical formula: $\mathrm{H}\left(-\mathrm{CH}_{2}-\mathrm{CH}_{2}-\mathrm{O}-\right)_{n}-\mathrm{OH}$.

Keeping these considerations in mind, we have synthesized, characterized and studied a new SPE (PEG) $)_{x} \mathrm{NH}_{4} \mathrm{I}$. We report here the effect of $8 \mathrm{MeV}$ electron irradiation and quenching at low temperature on the ionic conductivity of (PEG) ${ }_{x} \mathrm{NH}_{4} \mathrm{I}$ polymer salt complex. The PEG $(\mathrm{MW}=2000)$ used in our studies is a solid at room temperature with a melting point close to $50^{\circ} \mathrm{C}$. It has 46 repeat units $(n=46)$ and is highly crystalline. $\mathrm{NH}_{4}^{+}$is a cation with small radius $(1.4 \AA)$, which is favourable for the polymer-salt complex formation. $\mathrm{NH}_{4} \mathrm{I}$ is chosen as it fulfils the electrochemical stability criteria [6]. It has low lattice energy $\left(637 \mathrm{~kJ} \mathrm{~mol}^{-1}\right)$ [23]. $\mathrm{I}^{-1}$ is a large soft anion having low charge density which would help in reducing the ion-pair formation with $\mathrm{NH}_{4}^{+}$.

\section{Experimental}

The chemicals polyethylene glycol (PEG) of MW 2000 and $\mathrm{NH}_{4} \mathrm{I}$ procured from Fluka were used without further purification. The (PEG) ${ }_{x} \mathrm{NH}_{4} \mathrm{I}$ complexes (in the composition $x=15,20,30,46,70,100,150,200,300$ and 400 where $x$ is the ratio of the number of ether oxygens in one monomer unit of the polymer to each $\mathrm{NH}_{4}^{+}$ion of the salt) were prepared by the standard solution cast method using methanol as the common solvent [24]. All the samples were dried under vacuum for several hours before using them for measurements. The X-ray diffraction (XRD) patterns were recorded using a Scintag XDS 2000 diffractometer at a scan rate of 
Ionic conductivity in a new solid polymer electrolyte $(P E G)_{x} \mathrm{NH}_{4} I$

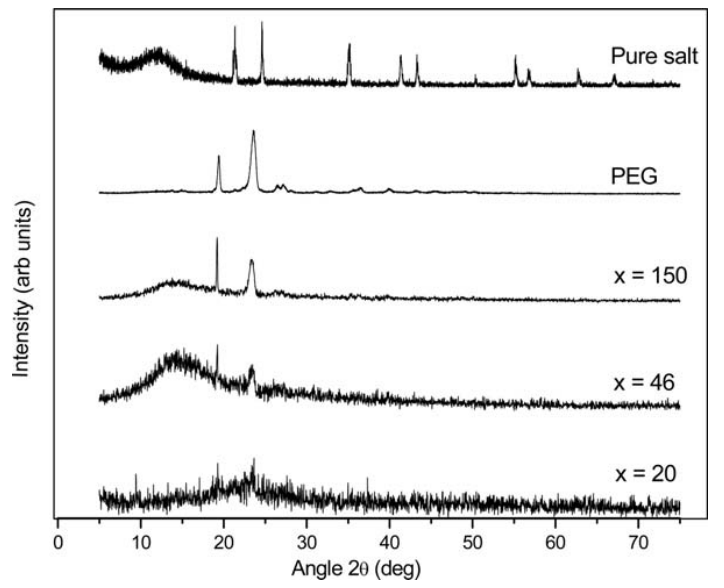

Figure 1. Powder XRD patterns of $(\mathrm{PEG})_{x} \mathrm{NH}_{4} \mathrm{I}$.

$10^{\circ} /$ min. Differential scanning calorimetry (DSC) measurements were carried out on a MDSC 2920 (TA Instruments, USA) in standard mode. ${ }^{1} \mathrm{H}$ Nuclear magnetic resonance (NMR) linewidth measurements were carried out on a Bruker DSX-300 spectrometer operating at $300 \mathrm{MHz}$ frequency. Ionic conductivity measurements were made using a dual phase lock-in-amplifier (PAR-5210) by the complex impedance method. To study the effect of ionizing radiation on ionic conductivity, selected compositions of the samples were exposed to a beam of $8 \mathrm{MeV}$ electrons to an accumulated dose of $10 \mathrm{kGy}$ and conductivity measurements were made immediately thereafter. Electron beam irradiation was carried out at Variable Energy Microtron Centre, Mangalore University, Mangalore, India. To study the effect of quenching, the samples were heated to its melting point of about $40-45^{\circ} \mathrm{C}$ and liquid nitrogen was poured on the molten sample. The rate of quenching was estimated to be about $20-25^{\circ} \mathrm{C} / \mathrm{s}$.

Since the samples with higher salt concentration are hygroscopic, there is a possibility of moisture contamination. Hence the samples were repeatedly dried under vacuum and repeated conductivity measurements were made to verify the reproducibility of the conductivity values. Consistence values of conductivity obtained after repeated vacuum drying rules out the possibility of water contamination. All the conductivity values are reported within an error margin of $5 \%$.

\section{Results and discussion}

\subsection{XRD measurements}

XRD patterns (shown in figure 1) were recorded for a few salt compositions of the polymer-salt complexes, as well as that for pure PEG and pure $\mathrm{NH}_{4} \mathrm{I}$ salt. Two prominent peaks of PEG (at $2 \theta=19.2$ and $23.4^{\circ}$ ) are present in all the patterns indicating the presence of pure polymer in all. The $\mathrm{NH}_{4} \mathrm{I}$ peaks are seen in none of the polymer-salt complexes indicating that $\mathrm{NH}_{4} \mathrm{I}$ solvates well in PEG-2000 


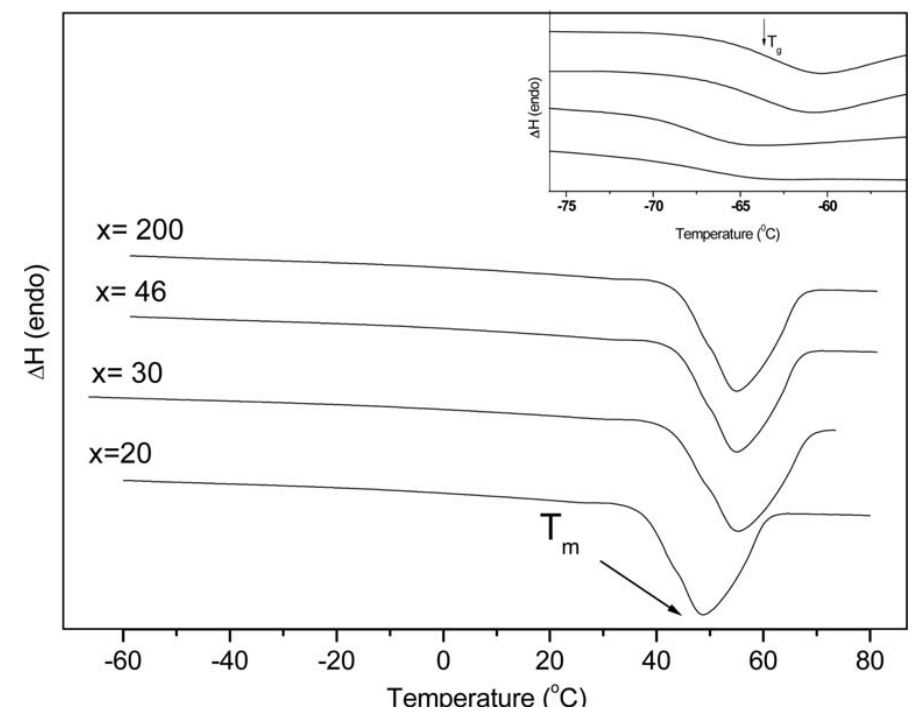

Figure 2. DSC traces (endothermic) of (PEG) $)_{x} \mathrm{NH}_{4} \mathrm{I}$. Inset shows the relevant regions magnified.

matrix. The intensity of the PEG peaks decreases at high salt concentrations. The diffraction peaks of the pure salt are absent in the polymer-salt complexes indicating the absence of pure salt phase in these complexes.

\subsection{DSC measurements}

Figure 2 shows the DSC curves (endothermic) registered for $(\mathrm{PEG})_{x} \mathrm{NH}_{4} \mathrm{I}(x=15$, 46, 70 and 100). The summary of the DSC results for the heating cycle is given in table 1. An increase in the glass transition temperature $T_{\mathrm{g}}$ with an increase in the salt concentration was observed and this signifies that the flexibility of the polymer chains decreases with an increase in the salt concentration in the polymer system. This reduction in flexibility of chains is usually interpreted as being a result of the effects of an increase in intramolecular and intermolecular coordinations between coordinating sites on the same or different polymer chains caused by the ions acting as transient cross links [25]. Melting temperature $T_{\mathrm{m}}$ of SPE system decreases as the salt content increases.

The enthalpy of melting $\Delta H_{\mathrm{m}}$ is less for the SPEs in comparison to that of pure PEG-2000. The area under the curve for the melting endotherm is related to the crystallinity of the specimen. The percentage or the degree of crystallinity $X_{\mathrm{c}}$ in the sample was estimated from the ratio of the enthalpy $\Delta H_{\mathrm{m}}$ of the samples and the enthalpy of melting of $100 \%$ crystalline PEG $\left(\Delta H_{\mathrm{m}}(\mathrm{PEG})=202.41 \mathrm{~J} / \mathrm{g}[26]\right)$. $X_{\mathrm{c}}$ decreases as the salt concentration increases (table 1). With an increase in $\mathrm{NH}_{4} \mathrm{I}$ salt concentration, $\Delta H_{\mathrm{m}}$ decreases indicating a decrease in $X_{\mathrm{c}}$ [27]. Similar results have been obtained in $\mathrm{PEG}_{x} \mathrm{LiClO}_{4} \mathrm{SPE}$ also [28]. The reduction in the crystalline fraction $X_{\mathrm{c}}$ with the increase in the salt concentration can be attributed to the inhibition of crystallization by the salt. 
Ionic conductivity in a new solid polymer electrolyte $(\mathrm{PEG})_{x} \mathrm{NH}_{4} \mathrm{I}$

Table 1. DSC results of $(\mathrm{PEG})_{x} \mathrm{NH}_{4} \mathrm{I}$.

\begin{tabular}{cccccc}
\hline$x$ & Salt in mole & $T_{\mathrm{m}}\left({ }^{\circ} \mathrm{C}\right)$ & $T_{\mathrm{g}}\left({ }^{\circ} \mathrm{C}\right)$ & $\Delta H_{\mathrm{m}}(\mathrm{J} / \mathrm{g})$ & $\%$ Crystallinity $X_{\mathrm{c}}$ \\
\hline 15 & 3.067 & 42.27 & $-62.80 \pm 1.0$ & 121.43 & 59.89 \\
20 & 2.300 & 41.73 & $-64.26 \pm 1.0$ & 135.79 & 67.09 \\
30 & 1.533 & 45.07 & $-62.40 \pm 1.0$ & 141.79 & 70.05 \\
46 & 1.000 & 45.73 & $-60.55 \pm 1.0$ & 143.79 & 71.03 \\
70 & 0.657 & 52.40 & $-59.80 \pm 1.0$ & 147.16 & 72.70 \\
100 & 0.460 & 52.86 & $-63.00 \pm 1.0$ & 147.75 & 73.00 \\
200 & 0.230 & 53.64 & - & 152.69 & 75.44 \\
400 & 0.115 & 53.92 & - & 165.75 & 81.89 \\
PEG & 0.000 & 55.00 & - & 168.00 & 83.00 \\
\hline
\end{tabular}

\section{$3.3{ }^{1} \mathrm{H}$ NMR results}

The ${ }^{1} \mathrm{H}$ NMR spectra for low salt compositions $(x>150)$ and for pure PEG consist of two components, a strong broad signal and a relatively narrow and weaker signal superimposed on top of it (figure 3). While the polymer-salt complexes of lower salt concentration still show two overlapping signals, for complexes of higher salt concentration $(x<150)$, the broad component merges with the baseline. Other workers also have observed this feature earlier $[29,30]$. It is generally known that the broad component is due to the crystalline regions and the narrow component corresponds to the amorphous regions. A Gaussian curve fits to the broad signal and a Lorentzian to the narrow signal. Figure 4 shows the variation of ${ }^{1} \mathrm{H}$ NMR linewidth as a function of salt concentration. As the salt concentration increases, the linewidth decreases sharply in a similar way to the decrease in $T_{\mathrm{g}}$ as observed in DSC measurements and reaches a minimum at around $x=20$ and then increases. Further increase in linewidth with salt concentration though $X_{\mathrm{c}}$ decreases could be due to the decrease in polymer chain flexibility as indicated by an increase in $T_{\mathrm{g}}$ at higher salt concentration. ${ }^{1} \mathrm{H}$ NMR signals for a few selected compositions of (PEG) $)_{x} \mathrm{NH}_{4} \mathrm{I}$ have been recorded as a function of temperature in the range 200$330 \mathrm{~K}$. Figure 5 exhibits the variation of ${ }^{1} \mathrm{H}$ NMR linewidths as a function of temperature. From the linewidth data, correlation times $\tau_{\mathrm{c}}$ 's have been calculated using the equation [31]

$$
\tau_{\mathrm{c}}=\frac{1}{\alpha \pi \Delta \nu} \times \tan \left[\frac{\pi}{2} \times\left(\frac{(\Delta \nu)^{2}-\left(\Delta \nu_{\mathrm{r}}\right)^{2}}{\left(\Delta \nu_{\mathrm{d}}\right)^{2}-\left(\Delta \nu_{\mathrm{r}}\right)^{2}}\right)\right],
$$

where $\tau_{\mathrm{c}}$ is the correlation time, $\alpha$ is a parameter of order unity, $\Delta \nu$ is the line width in the narrowing region (in $\mathrm{Hz}$ ), $\Delta \nu_{\mathrm{r}}$ is the residual linewidth and $\Delta \nu_{\mathrm{d}}$ is the rigid lattice linewidth. $\tau_{\mathrm{c}}$ 's were calculated at various temperatures. From the slope of the $\ln \left(\tau_{\mathrm{c}}\right)$ vs. $1000 / T$ plot, $E_{\mathrm{a}}$ and $\tau_{0}$ were estimated. The ionic conductivity $\sigma_{\mathrm{NMR}}$ was also calculated using the Nernst-Einstein relation

$$
\sigma_{\mathrm{NMR}}=\frac{N q^{2} d^{2}}{6 \tau_{\mathrm{c}} k T}
$$




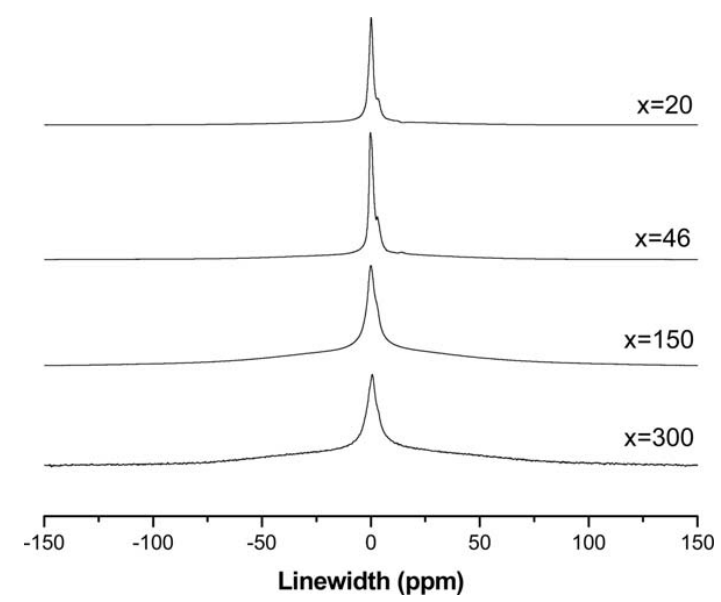

Figure 3. Room temperature ${ }^{1} \mathrm{H}$ NMR signals of $(\mathrm{PEG})_{x} \mathrm{NH}_{4} \mathrm{I}$ system, $x=20,46,150$ and 300 .

Table 2. Results of NMR parameters obtained from ${ }^{1} \mathrm{H}$ NMR linewidths for $(\mathrm{PEG})_{x} \mathrm{NH}_{4} \mathrm{I}$.

\begin{tabular}{rccccc}
\hline$x$ & $\tau_{0}(\mathrm{~s})$ & $E_{\mathrm{aNMR}}(\mathrm{eV})$ & $\tau_{c}$ at $300 \mathrm{~K}(\mathrm{~s})$ & $\sigma_{\mathrm{NMR}}(\mathrm{S} / \mathrm{cm})$ & $\sigma(\mathrm{S} / \mathrm{cm})$ \\
\hline 20 & $7.15 \times 10^{-12}$ & 0.254 & $6.53 \times 10^{-7}$ & $8.33 \times 10^{-5}$ & $4.77 \times 10^{-6}$ \\
46 & $5.95 \times 10^{-11}$ & 0.296 & $1.10 \times 10^{-6}$ & $1.06 \times 10^{-5}$ & $2.63 \times 10^{-6}$ \\
100 & $9.38 \times 10^{-15}$ & 0.520 & $5.14 \times 10^{-6}$ & $4.94 \times 10^{-5}$ & $4.78 \times 10^{-6}$ \\
\hline
\end{tabular}

where $N$ is the ammonium ion concentration per unit volume, $d$ is the average ionic jump distance and $q$ is the ionic charge. Considering an average interionic distance of $\sim 1.66 \pm 0.02 \AA$, the value of $N$ in $(\mathrm{PEG})_{x} \mathrm{NH}_{4} \mathrm{I}$ can be calculated from the molecular weights and densities of PEG and $\mathrm{NH}_{4} \mathrm{I}$ respectively, yielding $N \sim 1.4 \times 10^{26}$ $\mathrm{m}^{-3}$. Activation energy $E_{\mathrm{a}}(\mathrm{NMR})$ obtained from the plot of $\ln \tau_{\mathrm{c}}$ vs. $1000 / T$ and hence $\sigma_{\mathrm{NMR}}$ calculated using eq. (2) are tabulated and compared with the values obtained from complex impedance spectroscopy in table 2. As seen from the table, $\sigma_{\mathrm{NMR}}$ is much higher than that measured from the complex impedance plot. Such discrepancies have been observed earlier in the literature. This could be due to the sensitivity of NMR to local dynamics in contrast with the conductivity measurement, which measures only the long-range transport. Another reason for this difference could be that while conductivity measurement responds to the motion of only charged (i.e., dissociated) species, NMR can sense the motion of undissociated molecules as well. Such differences in the conductivities determined by the two techniques have been discussed earlier [32].

\subsection{Ionic conductivity measurements}

The ionic conductivity as a function of salt concentration (mole fraction) for $(\mathrm{PEG})_{x} \mathrm{NH}_{4} \mathrm{I}$ at $300 \mathrm{~K}$ is shown in figure 6 . The conductivity isotherm shows 
Ionic conductivity in a new solid polymer electrolyte $(P E G)_{x} \mathrm{NH}_{4} I$

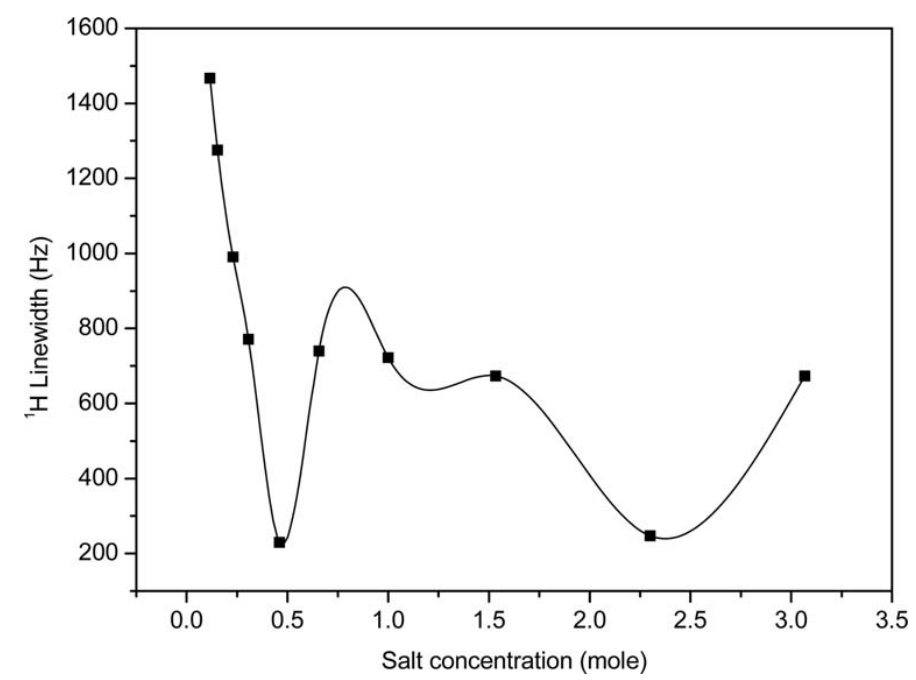

Figure 4. Room temperature ${ }^{1} \mathrm{H}$ NMR linewidths vs. salt concentration for $(\mathrm{PEG})_{x} \mathrm{NH}_{4} \mathrm{I}$ system.

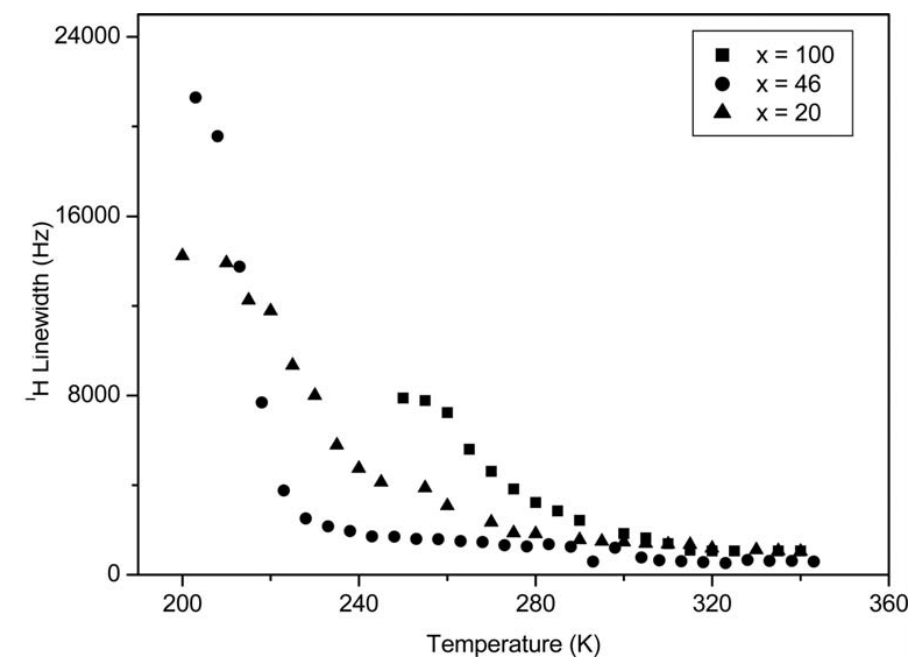

Figure 5. ${ }^{1} \mathrm{H}$ NMR linewidths vs. temperature plot for $(\mathrm{PEG})_{x} \mathrm{NH}_{4} \mathrm{I}$ system.

a characteristic double peak for $x=20$ and 70 with a conductivity maximum of about $4.7 \times 10^{-6} \mathrm{~S} / \mathrm{cm}$. The initial increase in conductivity in the low concentration systems is explained as due to the increase in charge carriers as the number of free cations increases and also a decrease in $X_{\mathrm{c}}$ with an increase in salt concentration. The further decrease in $\sigma$ though $X_{\mathrm{c}}$ decreases further at higher salt concentration could be due to an increase in the ion-ion interaction that impedes the motion of $\mathrm{NH}_{4}^{+}$and the stiffening of polymer chains as a result of cross-links formed by cations and salt precipitation [33]. Also, at higher salt concentration the formation 


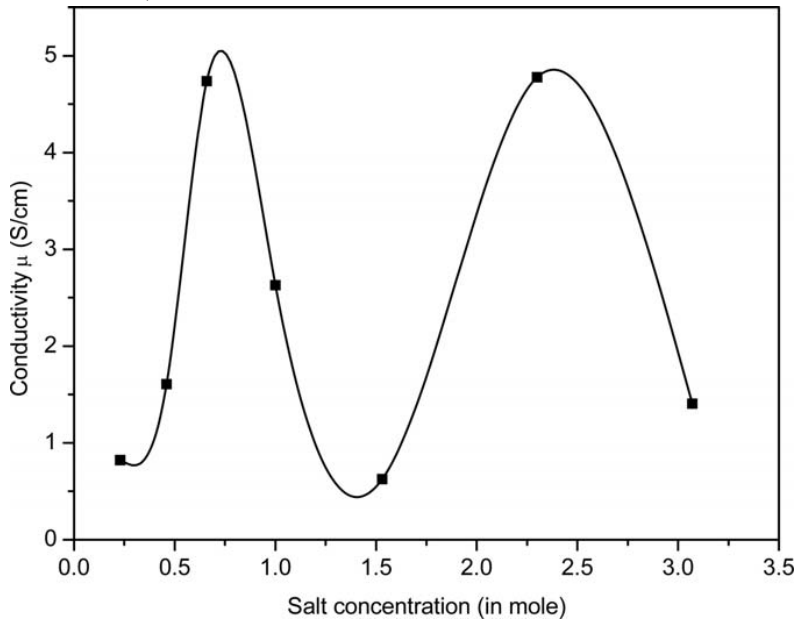

Figure 6. Variation of ionic conductivity with salt concentration in $(\mathrm{PEG})_{x} \mathrm{NH}_{4} \mathrm{I}$ system.

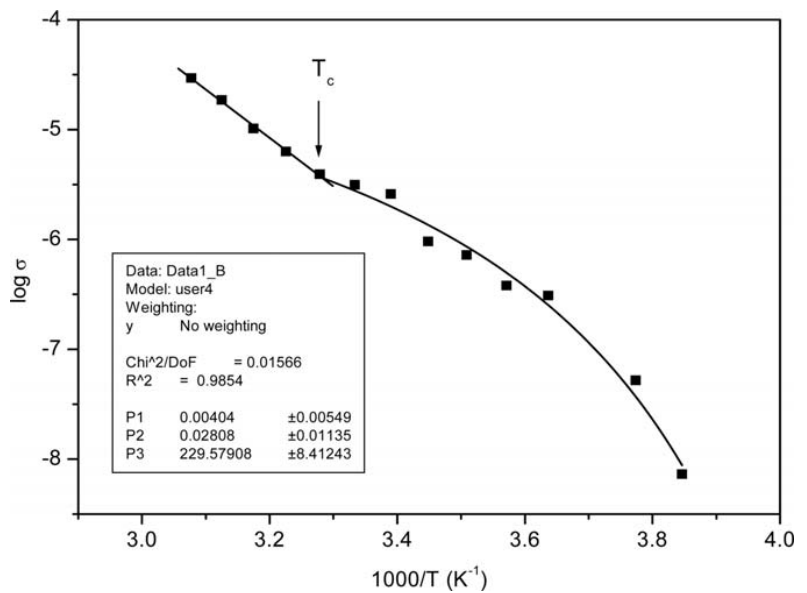

Figure 7. Conductivity vs. temperature plot for $(\mathrm{PEG})_{20} \mathrm{NH}_{4} \mathrm{I}$. The solid lines are fits to the Arrhenius (above $T_{\mathrm{c}}$ ) and the VTF (below $T_{\mathrm{c}}$ ) equations.

of ionic clusters too causes a decrease in mobility of charge carriers, since these large aggregates migrate slower than free ions because of their size. The observation of characteristic double peak in ionic conductivity has been well-established in the literature $[34,35]$.

Ionic conductivity has also been measured as a function of temperature for a few selected compositions of the salt. Figure 7 shows the variation of conductivity as a function of temperature for $(\mathrm{PEG})_{20} \mathrm{NH}_{4} \mathrm{I}$. The ionic conductivity increases monotonically as the temperature rises and reaches a high value $\sim 2.83 \times 10^{-4} \mathrm{~S} / \mathrm{cm}$ at $330 \mathrm{~K}$. From the temperature dependence experiments, it is seen that there exists a temperature $T_{\mathrm{c}}$ below which the conductivity plot has a curvature and above which it linearly and steeply raises till the melting temperature of the sample. The 
Ionic conductivity in a new solid polymer electrolyte $(P E G)_{x} \mathrm{NH}_{4} I$

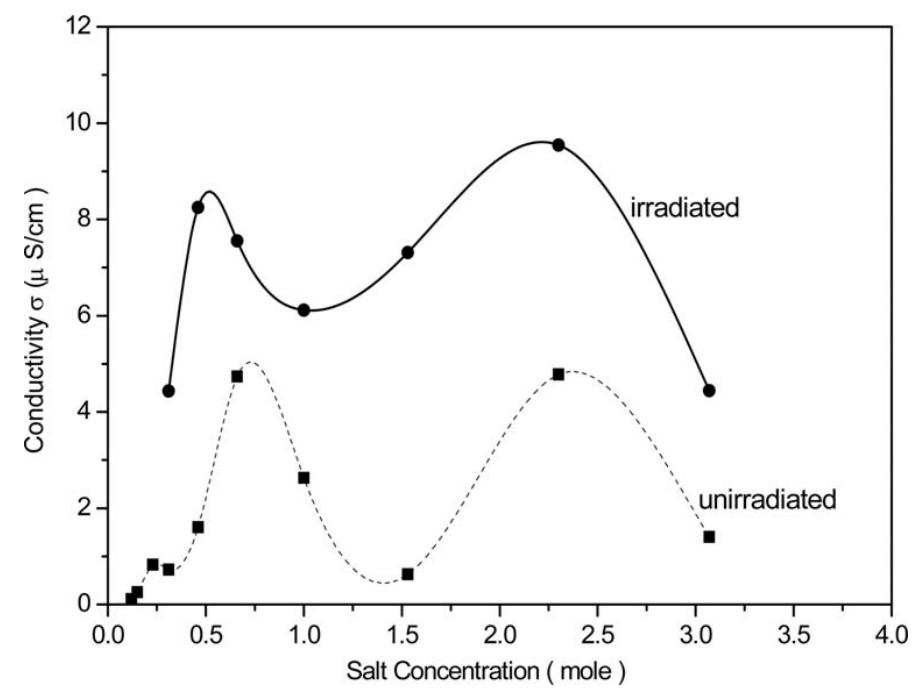

Figure 8. Ionic conductivity vs. salt concentration before and after electron beam irradiation in $(\mathrm{PEG})_{x} \mathrm{NH}_{4} \mathrm{I}$ system.

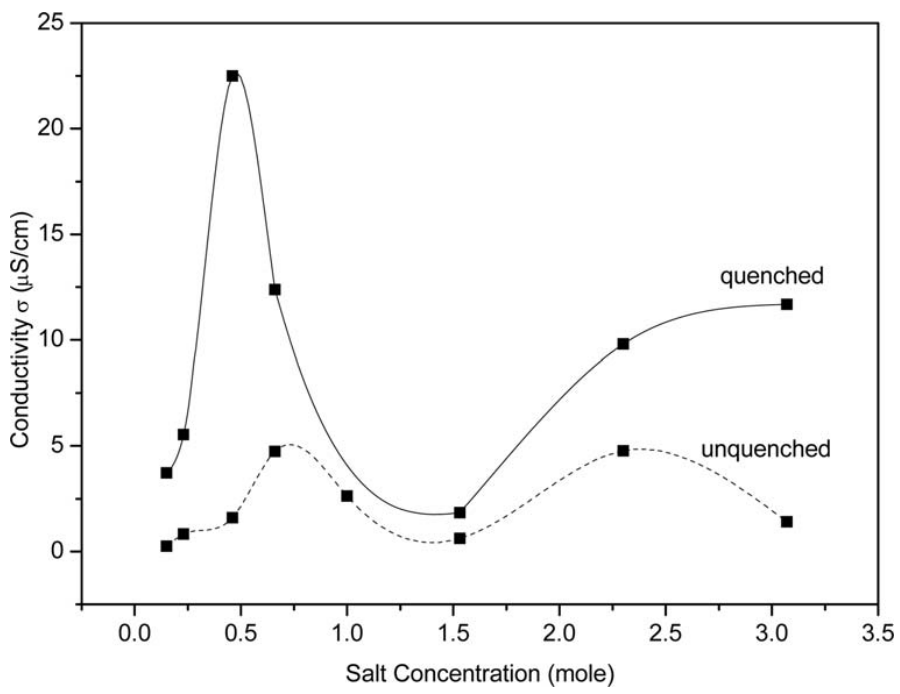

Figure 9. Ionic conductivity vs. salt concentration for $(\mathrm{PEG})_{x} \mathrm{NH}_{4} \mathrm{I}$ system before and after quenching.

region below $T_{\mathrm{c}}$ fits the empirical Vogel-Tamman-Fulcher (VTF) [36-38] equation

$$
\sigma=\frac{A}{\sqrt{T}} \exp \left(\frac{-B}{k\left(T-T_{0}\right)}\right)
$$

where $T$ is the absolute temperature and $T_{0}$ the ideal glass transition temperature that is usually $30-50^{\circ}$ below $T_{\mathrm{g}}$ (it is the temperature at which the configurational 


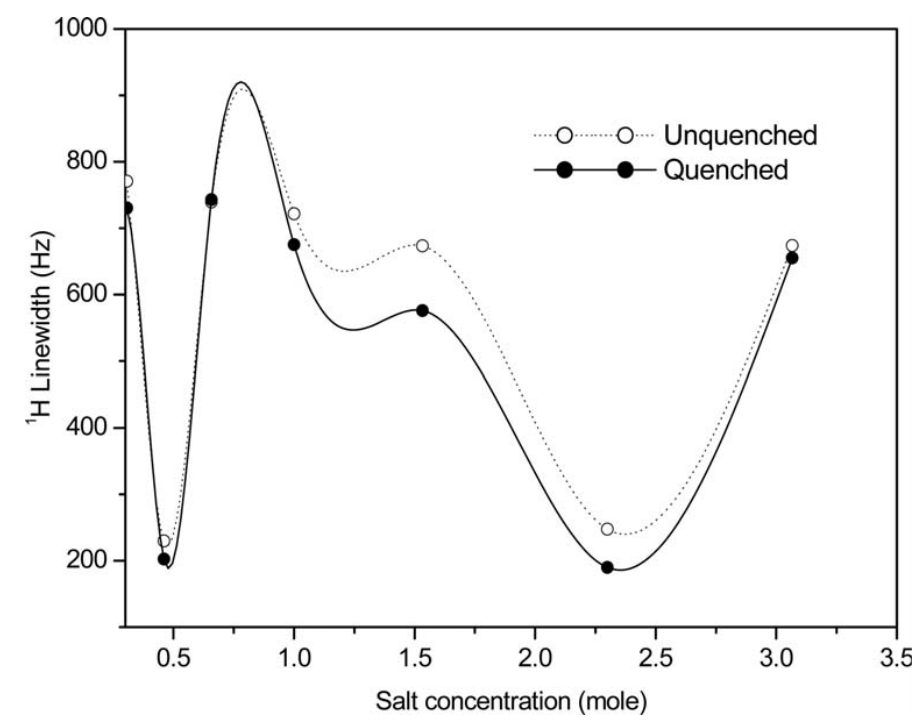

Figure 10. ${ }^{1} \mathrm{H}$ NMR linewidth as a function of salt concentration for $(\mathrm{PEG})_{x} \mathrm{NH}_{4} \mathrm{I}$ before and after quenching.

Table 3. Arrhenius and VTF equations fitting parameters for (PEG) ${ }_{20} \mathrm{NH}_{4} \mathrm{I}$.

\begin{tabular}{ccccccc}
\hline$x$ & Salt in mole & $E_{\mathrm{a}}(\mathrm{eV})$ & $T_{\mathrm{c}}(\mathrm{K})$ & $A\left(\mathrm{SK}^{0.5} \mathrm{~cm}^{-1}\right)$ & $B(\mathrm{eV})$ & $T_{0}(\mathrm{~K})$ \\
\hline 20 & 2.300 & 0.875 & 304 & 0.004 & 0.028 & 229.58 \\
\hline
\end{tabular}

entropy vanishes), $B$ is an apparent activation energy which is dependent on the free energy barrier opposing configurational rearrangements and $A$ is a pre-exponential factor related to the number of carriers [39]. The fitting parameter values are given in table 3. The Arrhenius equation

$$
\sigma=\sigma_{0} \exp \left(\frac{-E_{\mathrm{a}}}{k T}\right)
$$

(where the symbols have their usual meanings) fits the region above $T_{\mathrm{c}}$. The cross-over between Arrhenius and VTF behaviour of $\sigma(T)$ is widely reported and discussed in $[4,40]$.

\subsection{Effect of electron irradiation on ionic conductivity}

Figure 8 shows the observed conductivity changes as a function of salt concentration before and after electron irradiation in $(\mathrm{PEG})_{x} \mathrm{NH}_{4} \mathrm{I}$ system. Irradiating with $8 \mathrm{MeV}$ electron beam has resulted in the increase in the ionic conductivity by nearly one order. The increase in conductivity is seen in almost all salt compositions. However, the increase is more pronounced in the medium salt concentration 
Ionic conductivity in a new solid polymer electrolyte $(P E G)_{x} \mathrm{NH}_{4} I$

Table 4. DSC results of quenched (PEG) ${ }_{x} \mathrm{NH}_{4} \mathrm{I}$.

\begin{tabular}{|c|c|c|c|c|c|c|c|}
\hline \multirow[b]{2}{*}{$x$} & \multirow{2}{*}{$\begin{array}{l}\text { Salt } \\
\text { content } \\
\text { in mole }\end{array}$} & \multicolumn{2}{|c|}{$T_{\mathrm{m}}\left({ }^{\circ} \mathrm{C}\right)$} & \multicolumn{2}{|c|}{$T_{\mathrm{g}}\left({ }^{\circ} \mathrm{C}\right)$} & \multicolumn{2}{|c|}{$\%$ Crystallinity } \\
\hline & & Unquenched & Quenched & Unquenched & Quenched & Unquenched & Quenched \\
\hline 15 & 3.067 & 42.3 & 50.4 & -62.80 & -60.9 & 59.89 & 47.03 \\
\hline 20 & 2.300 & 41.7 & 51.5 & -64.26 & -45.3 & 67.09 & 46.13 \\
\hline 30 & 1.533 & 45.1 & 50.7 & -62.40 & -45.3 & 70.05 & 49.41 \\
\hline 46 & 1.000 & 45.7 & 51.5 & -60.54 & - & 71.03 & 51.05 \\
\hline 70 & 0.657 & 52.4 & 52.8 & -46.40 & -49.7 & 72.70 & 56.92 \\
\hline 100 & 0.460 & 55.9 & 54.1 & -58.65 & -49.3 & 73.00 & 58.53 \\
\hline 150 & 0.307 & 52.8 & - & - & - & 75.44 & 62.76 \\
\hline 200 & 0.230 & 54.2 & 54.3 & - & - & 81.89 & 71.18 \\
\hline 300 & 0.153 & - & - & - & - & - & - \\
\hline 400 & 0.115 & 54.4 & 54.8 & - & - & - & - \\
\hline PEG & 0.000 & 55.0 & - & - & - & 168.00 & - \\
\hline
\end{tabular}

range $x=20$ and 100. The maximum conductivity achieved after irradiation is $9.63 \times 10^{-6} \mathrm{~S} / \mathrm{cm}$ for $x=20$. The increase in conductivity after electron beam irradiation could be due to the increase in the amorphous content of the sample. The electrolyte samples were irradiated by $8 \mathrm{MeV}$ electrons to three different doses $(5,10$ and $15 \mathrm{kGy})$ and conductivity measurements were made. Ionic conductivity is found to increase by the same order after each accumulated dose. However, maximum enhancement in conductivity is observed after irradiation to an intermediate dose of $10 \mathrm{kGy}$. The results are thus reported only for the dose of $10 \mathrm{kGy}$. Conductivity measurements were carried out over a period ranging from a few hours to several months after irradiation. The observation is that there is hardly any change in the values of conductivity. This would indicate that the irradiation-induced effects are permanent in nature.

\subsection{Effect of quenching on ionic conductivity}

Figure 9 depicts the observed conductivity changes as a function of salt concentration before and after quenching. The process of quenching enhances the ionic conductivity by one to two orders of magnitudes. It is observed that the conductivity enhancement is seen in all salt compositions. The maximum conductivity after quenching is found to be $2.26 \times 10^{-5} \mathrm{~S} / \mathrm{cm}$ for $x=100$. Table 4 shows the DSC results obtained before and after quenching. The percentage of crystallinity is found to decrease in almost all salt compositions after quenching. The DSC studies reveal that increase in the conductivity is more due to the increase in the amorphous content (or decrease in crystallinity) of the system after quenching. ${ }^{1} \mathrm{H}$ NMR linewidths were also recorded at room temperature for both quenched and unquenched systems (figure 10). The process of quenching is found to decrease the linewidth marginally. The lowest linewidth is observed for $x=100$ concentration, for which the quenching process has shown maximum enhancement in ionic conductivity. 


\section{Conclusions}

A new solid polymer electrolyte $(\mathrm{PEG})_{x} \mathrm{NH}_{4} \mathrm{I}$ were synthesized, characterized and studied using XRD, DSC, NMR and AC conductivity techniques. XRD results confirm the formation of polymer-salt complex. The samples with higher salt concentrations are softer and moderately hygroscopic. Samples of intermediate salt concentrations are less hygroscopic and show higher ionic conductivity. The room temperature conductivity is highest $\left(4.78 \times 10^{-6} \mathrm{~S} / \mathrm{cm}\right)$ for $x=20$ and 70 . At low salt concentrations they are highly crystalline and less hygroscopic and have moderate room temperature conductivity of the order of $10^{-7} \mathrm{~S} / \mathrm{cm}$. As the salt concentration increases they become more amorphous leading to increase in conductivity. The concentration dependence of conductivity shows characteristic peaks for intermediate salt concentration $(x=20$ and 70$)$. The glass transition temperature is minimum for intermediate salt concentration $(x=20)$ and for all other salt concentrations $T_{\mathrm{g}}$ is higher due to stiffening of the polymer chains due to crosslinking among them. $T_{\mathrm{m}}$ of samples is lower than the pure PEG-2000. The degree of crystallinity $X_{\mathrm{c}}$ is observed to decrease with an increase in salt concentration. This reduction in $X_{\mathrm{c}}$ is attributed to the lower $T_{\mathrm{m}}$ and decrease in heat of melting $\Delta H_{\mathrm{m}}$ with the increase in salt concentration. ${ }^{1} \mathrm{H}$ NMR linewidths and DSC results are consistent with the room temperature conductivity results. The ionic conductivity increases monotonically with temperature and reaches a maximum value of $2.83 \times 10^{-4} \mathrm{~S} / \mathrm{cm}$ at temperature $330 \mathrm{~K}$. The temperature dependence of conductivity fits the Arrhenius and VTF equations at different temperature ranges.

The process of exposing the solid polymer electrolytes to electron beam and also quenching to liquid nitrogen temperature gives rise to an increase in conductivity by nearly one order of magnitude. Exposure of the present polymer electrolytes to electron beam may have resulted in the increase in the amorphous fraction of the complex and hence decrease in the degree of crystallinity. Of the two methods of conductivity enhancement, quenching appears to be more effective giving rise to a maximum conductivity of $2.26 \times 10^{-5} \mathrm{~S} / \mathrm{cm}$ for $x=100$.

The radiation damage in polymer electrolyte is also known to cause chain scission (fragmentation) and cross-linking. Chain scission leads to a higher flexibility of polymer chains. Cross-linking leads to a decrease in the flexibility of polymer segments (resulting in a decrease in conductivity). Perhaps in the present system, irradiation may also has resulted in chain scission resulting in the increase in the flexibility of polymer chains and hence the conductivity enhancement. Thus, irradiation of SPEs by ionizing radiation and also quenching at low temperature appear to be promising methods to enhance ionic conductivity in known solid polymer electrolytes.

\section{Acknowledgements}

One of the authors (P N Kulkarni) thanks the University Grants Commission, Government of India, for FIP-Teacher Fellowship and financial assistance. The authors thank Prof. A V Chadwick, University of Kent, UK for his help in DSC 
measurements. The authors also thank Mr Madhurjya M Borgohain for his help during the conductivity measurements.

\section{References}

[1] D E Fenton, J M Parker and P V Write, Polymer 14, 589 (1973)

[2] P V Write, Br. Polym. J. 7, 319 (1975)

[3] V Chandrashekar, in: Advances in polymer science edited by S Edwards (Springer Verlag, Berlin, 1996) Vol. 135, pp. 139-205

[4] A Ratner, in: Polymer electrolytes reviews edited by J R MacCallum and C A Vincent (Elsevier Appl. Sci. London, 1987 and 1989), Vol. 1 and 2

[5] M B Armand, Ann. Rev. Mater. Sci. 16, 245 (1986)

[6] C A Vincent, Prog. Solid State Chem. 17, 145 (1987)

[7] M Watanabe and N Ogata, Br. Polym. J. 17, 145 (1988)

[8] M A Ratner and D F Shriver, Chem. Rev. 88, 109 (1988)

[9] R Hug, G C Farrington, R Koksbang and P E Tonder, Solid State Ionics 57, 277 (1992)

[10] A M Sukeshini, A R Kulkarni and A Sharma, Solid State Ionics 113-115, 179 (1998)

[11] F Croce, G B Appetecchi, L Persi and B Scrosati, Nature (London) 394, 456 (1998)

[12] H Sun, H J Sohn, O Yamatomo, Y Takeda and N Imanishi, J. Electrochem. Soc. 146, 1672 (1999)

[13] Th Joykumar Singh, T Mimani, K C Patil and S V Bhat, Solid State Ionics 154-155, 21 (2002)

[14] Th Joykumar Singh and S V Bhat, J. Power Sources 129, 280 (2004)

[15] Joykumar S Thokchom, Christina Chen, K M Abraham and Binod Kumar, Solid State Ionics 176, 1887 (2005)

[16] A G Bishop, D R MacFarlance, McNaughton and M Forsyth, J. Phys. Chem. 11, 2237 (1996)

[17] Th Joykumar Singh, Ganesh Sanjeev, K Siddappa and S V Bhat, J. Polym. Sci. Part B: Polym. Phys. 42, 1299 (2004)

[18] W H Meyer, Adv. Mater. 102, 352 (1998)

[19] C Berthier, W Gorecki, M Minier, M B Armand, J M Chabagno and P Rigaud, Solid State Ionics 11, 91 (1983)

[20] J Shi and C A Vincent, Solid State Ionics 60, 11 (1993)

[21] R K Gupta, H Y Jung and C M Whang, J. Mater. Chem. 12, 3779 (2002)

[22] Y Kato, K Hasumi, S Yokoyama, T Yabe, H Ikuta, Y Uchimoto and M J Wakihara, Thermal Analysis and Calorimetry 69, 889 (2002)

[23] H D B Jenkins and D F C Morris, Mol. Phys. 32(1), 231 (1976)

[24] Nader Binesh and S V Bhat, Solid State Ionics 92, 261 (1996)

[25] J F Le Nest, A Gandini and H Cheradane, Br. Polym. J. 20, 253 (1988)

[26] X Li and S L Hsu, J. Polym. Sci., Polym. Phys. Ed. 22, 1331 (1984)

[27] M Watanabe, M Togo, K Sanui, N Ogata, T Kobayashi and Z Ohtaki, Macromolecules 17, $2908(1984)$

[28] T Joykumar Singh and S V Bhat, Bull. Mater. Sci. 26, 707 (2003)

[29] K Hikichi and J Furuichi, J. Polym. Sci. A3, 3003 (1965)

[30] A Johansson, A Wendsjö and Tegenfeldt, J. Electrochim. Acta 37, 1487 (1992)

[31] J R Hendrickson and P J Bray, J. Magnetic Resonance 9, 341 (1973)

[32] D Brinkmann, Progress in NMR Spectroscopy 24, 527 (1992). 
[33] F M Gray, Solid polymer electrolyte - Fundamentals and technological applications (VCH Inc., New York, 1991)

[34] F M Gray, Solid State Ionics 40-41, 637 (1990)

[35] C D Robitaille and D Fauteux, J. Electrochem. Soc. 133, 315 (1986)

[36] H Vogel, Phys. Z22, 645 (1922)

[37] V G Tamman and H Z Hesse, Anorg. Allg. Chem. 19, 245 (1926)

[38] G H Fulcher, J. Am. Ceram. Soc. 8, 339 (1925)

[39] J H Gibbs and E A DiMarzio, J. Chem. Phys. 28, 373 (1958)

[40] N Binesh and S V Bhat, J. Polym. Sci. Part B: Polym. Phys. 36, 1201 (1998) 